\title{
PERAN PEMERINTAH DESA DALAM PENANGGULANGAN NARKOBA MELALUI PENYULUHAN HUKUM DI DESA JURU MAPIN KECAMATAN BUER SUMBAWA
}

\author{
Siti Hasanah"1), Ibrahim²), Adi Supriyadi'1), Sri Rejeki ${ }^{3)}$ \\ 1)IImu Fakultas Hukum Universitas Muhammadiyah Mataram, Mataram, Nusa Tenggara Barat, Indonesia \\ 2) Pendidikan Geografi FKIP Universitas Muhammadiyah Mataram, Mataram, Nusa Tenggara Barat, Indonesia \\ 3)Pendidikan PKn FKIP Universitas Muhammadiyah Mataram, Mataram, Nusa Tenggara Barat, Indonesia \\ Corresponding author : Siti Hasanah \\ E-mail : magaparang1@gmail.com
}

Diterima 26 April 2021, Direvisi 28 Juli 2021, Disetujui 28 Juli 2021

\begin{abstract}
ABSTRAK
Penyebaran narkoba di Indonesia sudah masuk dalam zona kritis. Area penyebarannya semakin luas dan menyasar segala kalangan. Fenomena tersebut membutuhkan upaya penanganan dan penanggulangan serius dari seluruh elemen masyarakat. Salah satu strategi efetif penanggulangan narkoba dapat dilakukan melalui peningkatan peran pemerintah desa dalam melaksanakan tugas pembinaan masyarakat sebagaimana dimanatkan dalam Pasal 26 (1) Undang undang No 6 Tahun 2014 Tentang Desa. Sebagai ujung tombak pelaksana tugas pemerintah dalam struktur pemerintahan terendah, pemerintah desa bertanggungjawab dalam hal penanggulangan dan penanganan problem sosial seperti masalah narkoba. Strategi penanggulangan narkoba dapat dilakukan melalui program penyuluhan hukum oleh institusi terkait secara kontinu kepada masyarakat di tingkat desa. Program tersebut menjadi sarana transfer pengetahuan dan pemahaman yang efektif kepada masyarakat desa tentang dampak dan bahaya narkoba terhadap diri pribadi, ketertiban dan ketentraman lingkungan.
\end{abstract}

Kata kunci: penguatan peran; pemerintah desa; penanggulangan narkoba

\begin{abstract}
The spread of drugs in Indonesia has entered a critical zone. The area of its spread is getting wider and targets all circles. This phenomenon requires serious handling and overcoming efforts from all elements of society. One of the effective strategies for dealing with drugs can be done through increasing the role of the village government in carrying out community development tasks as stipulated in Article 26 (1) of Law No. 6 of 2014 on Villages. As the spearhead of implementing government tasks in the lowest government structure, the village government is responsible for overcoming and handling social problems such as drug problems. A drug control strategy can be carried out through a legal counseling program by related institutions continuously to the community at the village level. The program is a means of effective transfer of knowledge and understanding to the village community about the impact and dangers of drugs on individuals, environmental order and tranquility.
\end{abstract}

Keywords: role strengthening; village government; drug management

\section{PENDAHULUAN}

Di Indonesia, awal penyebaran narkoba cenderung menyasar kalangan-kalangan tertentu dalam klaster kehidupan modern diwilayah perkotaan dan kelas ekonomi menengah keatas seperti kalangan artis, dan pengusaha. Fenomena tersebut saat ini meluas dan menyasar segala kalangan baik masyarakat perkotaan maupun pedesaan. Fakta tersebut dapat dilihat dari tingkat penyebaran kasus narkoba yang hampir merambah berbagai pelosok negeri. Kasus narkoba mendominasi angka kriminalitas sepanjang Januari hingga November 2020. Ada peningkatan kasus dari 34.332 pada 2019 menjadi 34.639 di tahun ini. "Naik 300 perkara atau 0,89 persen," kata kata Karo Penmas Divisi Humas Polri Brigjen Awi Setiyono saat dikonfirmasi di Jakarta, Selasa, 8 Desember 2020. Khusus di Provinsi NTB kasus narkoba secara umum menurun dari 292 kasus atau 37,24\% dari 784 kasus di Tahun 2019 menurun menjadi 492 Kasus di Tahun 2020, sebagaimana dilansir dari hasil pengungkapan Kasus Narkotika BNNP NTB dan Jajaran Polda NTB di Tahun 2020. Walaupun terjadi penurunan jumlah kasus narkoba yang mampu terungkap, namun terjadi perluasan penyebaran narkoba khususnya di Kabupaten Sumbawa yaitu dari 157 desa yang ada dalam 
wilayah administrasi Kabupaten Sumbawa hampir seluruhnya terpapar narkoba. (Sumbawa, 2020)

Fenomena penyebaran narkoba yang semakin meluas khususnya di Kabupaten Sumbawa menjadi tugas berat seluruh elemen masyarakat untuk mendeklarasikan perang melawan narkoba. Banyak strategi yang dapat dilakukan dalam upaya memberantas narkoba baik sebagai upaya antisipasi maupun penanggulangan. Salah satu strategi efektif dalam mengantisipasi atau menanggulangi penyebaran narkoba adalah melalui program penyuluhan hukum. Program ini sebagai wujud peningkatan peran pemerintah desa yang dilakukan secara kontinu dengan sistem kerjasama dengan instansi terkait seperti akademisi maupun aparat penegak hukum. Alasan mendasar keterpilihan wilayah desa sebagai basis atau sasaran penyuluhan hukum tentang narkoba adalah sebagai upaya mempersempit area penyebaran infomasi dan sosialisasi dengan tujuan untuk memaksimalkan serapan dan pemahaman masyarakat.

\section{METODE}

Metode yang digunakan dalam penyuluhan hukum adalah metode ceramah dimana materi ditayangkan melalui slide presentasi yang dikemas secara menarik, untuk memberikan gambaran jelas dan lengkap kepada masyarakat terkait permasalahan narkoba. Selain itu materi juga dibagi kepada peserta penyuluhan dalam bentuk hard copy. Kegiatan penyuluhan hukum diikuti oleh tokoh masyarakat, tokoh agama, tokoh pemuda, pegiat perempuan dan anak, ibu PKK, dan stap pemerintah Desa, anggota BPD Desa Juru Mapin Kecamatan Buer Kabupten Sumbawa

\section{HASIL DAN PEMBAHASAN}

Kegiatan ini dilakukan dengan menggunakan tiga tahap diantaranya: pembukaan, pelaksanaan dan penutupan. Ketiga tahap ini dilakukan pada lokasi pada kantor Desa Jurumapin Kecamatan Buer Kabupaten Sumbawa.

\section{Acara pembukaan}

Kegiatan pengabdian kepada masyarakat melalui penyuluhan hukum sebagai bentuk peran pemerintah desa dalam penanggulangan narkoba di Desa Jurumapin Kecamatan Buer Kabupaten Sumbawa. Kegiatan pembukaan dihadiri tokoh masyarakat, tokoh agama, tokoh pemuda, pegiat perempuan dan anak, anggota BPD Desa Juru Mapin dan staff desa (Gambar 1). Pembukaaan ini dilakukaan langsung dengan pembukaan langsung oleh Kepala Desa Jurumapin Kecamatan Buer Kabupaten Sumbawa.

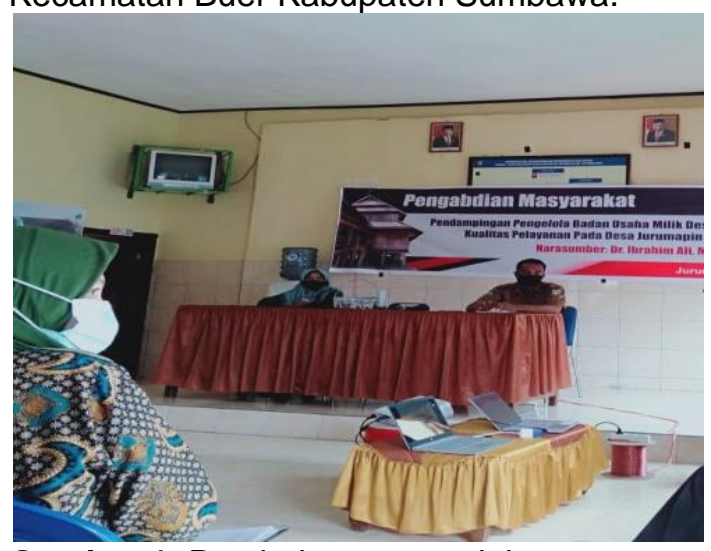

Gambar 1. Pembukaan penyuluhan

\section{Pelaksanaan Kegiatan}

Pelaksanaan kegiatan ini dimulai dengan menyiapkan fasilitas absensi, masker, botol hand sanitizer dan memasang spanduk. Pelaksanan kegiatan dimulai dengan pembukaan. Pembukaan kegiatan dilakukan langsung oleh Kepala Desa Jurumapin Kecamatan Buer Kabupaten Sumbawa Besar (Gambar 2).

Masalah penyalahgunaan narkoba mempunyai dimensi yang luas dan kompleks, baik dari sudut medik, psikiatri, kesehatan jiwa, maupun psikososial. Pengguna narkoba dapat merusak tatanan kehidupan keluarga, lingkungan masyarakat dan lingkungan sekolahnya, bahkan langsung atau tidak langsung merupakan ancaman bagi kelangsungan pembangunan serta masa depan bangsa dan negara Indonesia.Mencermati perkembangan peredaran dan pemakaian narkoba di kalangan remaja sungguh sangat mengkhawatirkan, karena narkoba jelas mengancam langsung masa depan anak-anak bangsa. Untuk itu, diperlukan suatu kesadaran sosial dalam memerangi peredaran narkoba dengan melibatkan seluruh potensi yang ada mulai dari unsur aparat penegak hukum, birokrasi serta anggota masyarakat bahu membahu dalam sinergi yang berkesinambungan, sehingga generasi muda dapat terhindar dari bujuk rayu untuk mengkonsumsi narkoba.
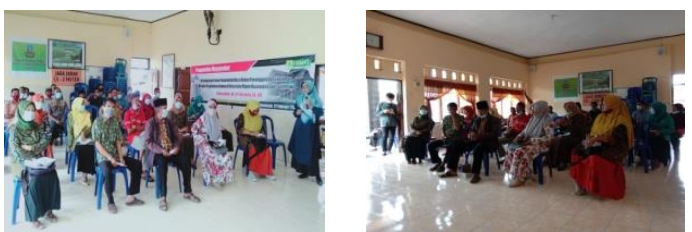

Gambar 2. Pelaksanaan kegiatan penyuluhan 
Hasil kegiatan ini memiliki manfaat bagi desa diantaranya :

1. Peran Pemerintah Desa dalam Penanggulangan Narkoba

a) Sebelum Penyuluhan Hukum

Secara umum penyelengaraan pemerintahan di desa Juru Mapin Kecamatan Buer Kabupaten Sumbawa, NTB merujuk pada UU Nomor 6 Tahun 2014 tentang Des (Jogloabang, 2020) Pasal 23 Pemerintahan Desa diselenggarakan oleh Pemerintah Desa. Pemerintah Desa yang dimaksud dalam tulisan ini adalah Kepala Desa (Pasal 25 UU Nomor 6 Tahun 2014 tentang Desa) (Undang - Undang no 6 Tahun 2014, 2014)

Pelaksanaan peran dan fungsi kepala desa secara umum mengacu pada ketentuan yang bersifat umum meliputi pemerintahan desa, pelaksanaan pembangunan desa, pembinaan kemasyarakatan desa, dan pemberdayaan masyarakat desa. Ada kecendrungan pelaksanaan fungsi dan tugas kepala desa mengedepankan program bersifat administrative, pembangunan sarana dan prasarana serta pemberdayaan masyarakat, namun program pembinaan kemasyarakat dikesampingkan.

b) Setelah Penyuluhan Hukum

Program penyuluhan hukum tentang Peningkatan Peran Pemerintah Desa Dalam Penanggulangan Narkoba membuka wawasan pemerintah desa terkait penyelarasan, pemerataan dan pendistribusian program pemerintah di Desa Juru Mapin Kecamatan Buer Sumbawa. Program pembinaan masyarakat yang selama ini cenderung dikesampingkan dalam perencanaan program pemerintah desa sudah mulai di maksimalkan, salah satunya melalui program penyuluhan hukum yang akan dilakukan secara kontinu dengan sistem kerjasama dengan institusi terkait.

2. Pemahaman Masyarakat Tentang Narkoba a). Sebelum Penyuluhan Hukum

Masyarakat beranggapan bahwa permasalahan narkoba merupakan tren zaman yang lumrah terjadi, sehingga penyeberannya bukanlah hal yang penting untuk disikapi. Pandangan tersebut juga terstigma dalam kehidupan masyarakat pedesaan sebagaimana terjadi di Desa Juru
Mapin Kecamatan Buer kabupaten Sumbawa. Pandangan tersebut sebagai imbas ketidaktahuan masyarakat tentang bahaya narkoba dan konsekuensi hukum serta dampaknya terhadap diri dan lingkungan masyarakat.

b). Setelah Penyuluhan Hukum

Program penyuluhan membuka wawasan dan pemahaman masyarakat tentang bahaya narkoba terhadap diri dan lingkungan serta bagaimana upaya mengantisipasi, mendeteksi dan menanggulangi penyebaran narkoba dalam lingkup keluarga dan masyarakat.

Pemahaman hukum terhadap penyuluhan tentang narkoba ditengah masyarakat. Narkoba sangat berbahanya bagi tubuh kita karena dampak yang ditimbulkan akibat penyalahgunaannya dapat merusak fungsi selsel syaraf. Peredaran dan penyalahgunaan narkoba di Indonesia semakin meningkat, terutama di kota besar, termasuk Kota Semarang. Perlu diberikan pemahaman kepada masyarakat khususnya generasi muda tentang bahaya narkoba. Pengabidan kepada masyarakat dengan penyuluhan hukum ini bertujuan untuk memberikan pengetahuan dan pemahaman tentang jenis-jenis narkoba, akibat penyalahgunannya, modus peredarannya, dan bagaimana cara pencegahannya. Sebagai mitra adalah Bhabinkamtibmas Polek Genuk, Karang Taruna, Rt, dan RW Desa Gebangsari, Kecamatan Genuk, Kota Semarang. Peserta antusias mengikuti kegiatan terlihat dari pertanyaan dan tangggapan yang disampaikan kepada pemateri. Hasil yang dicapai dari kegiatan ini adalah masyarakat lebih mengetahui dan memahami bahaya penyalahgunaan narkoba dan modus peredarannya sehingga dapat melakukan pencegahan. (Salatun \& Mina, 2019), (Widayati \& Winanto, 2021) dan (Sulistyawati et al., 2020)

\section{Evaluasi kegiatan dan Penutupan}

Kegiatan penyuluhan ini dilakukan selama sehari penuh dengan penutupan dilakukan langsung oleh Kepala Desa Jurumapin Kecamatan Buer Kabupaten Sumbawa (Gambar 3). 


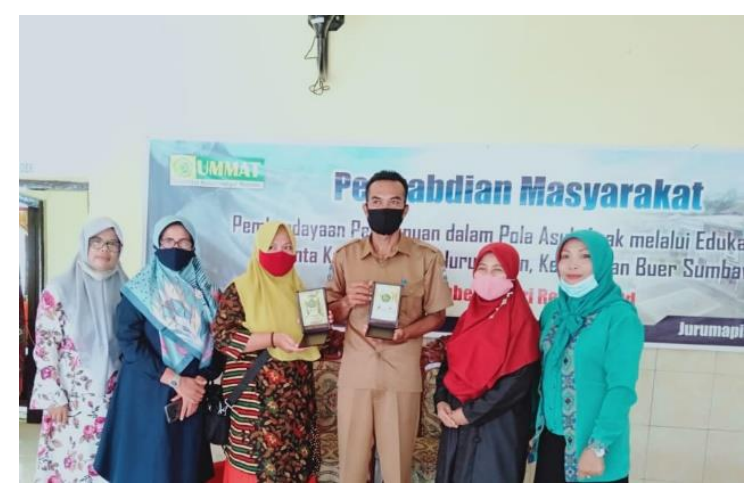

Gambar 3. Evaluasi dan penutupan acara

Kegiatan ini mendapat perhatian penuh dari semua masyarakat terutama kesadaran akan penting informasi tentang narkoba. Pada penyuluhan ini peserta juga diajarkan bagaimana cara-cara mendeteksi secara dini seseorang yang terkena Narkotika dengan melihat ciri-cirinya yang dikemas dalam bentuk lembar slide power point agar mereka dapat andil dalam mengantisipasi secara dini menyebarnya penggunaan Narkoba di lingkungannya. Selain itu juga dilakukan penayangan 2 judul film tentang bahaya Narkoba dan kisah nyata korban Narkoba. Kesemua metode tersebut diterapkan bersama- sama dalam acara penyuluhan selama 4 hari. Setelah pelaksanaan pengabdian masyarakat dimana tim PKM melakukan penyuluhan pada masyarakat Desa Bandar Khalifah, hasilnya masyarakat menyatakan cukup mengerti tentang bahaya penyalahgunaan narkotika, sehingga menambah pengetahuan dan wawasan mereka untuk menghindari dan menjaga agar anggota keluarga dan anggota masyarakat Desa Bandar Khalifah terbebas dari penyalahgunaan Narkotika (Setyawan \& Sulistyawati, 2019)

\section{SIMPULAN DAN SARAN}

Pemerintah desa adalah pemegang kewenangan penyelenggaraan pemerintahan dalam struktur pemerintahan terendah di Indonesia. Legal formal pelaksanaan peran pemerintah desa tercermin dalam distribusi tugas kepala desa sebagaimana diatur dalam Pasal 26 ayat (1) UU Nomor 6 Tahun 2014 tentang Desa. Salah tugas kepala desa adalah melakukan pembinaan kemasyarakatan desa. Tugas ini secara faktual cenderung dikesampingkan, sehingga berimbas pada rendahnya pemahaman dan pengetahuan masyarakat terhadap berbagai problem sosial diantaranya masalah penanggulangan narkoba. Kasus narkoba di Indonesia sudah masuk dalam zona kritis yang tingkat penyebarannya sudah merambah kesegala pelosok negeri, termasuk di wilayah Kabupaten Sumbawa.
Fenomena tersebut perlu upaya penanganan serius oleh seluruh elemen masyarakat. Program penyuluhan hukum sebagaimana dilakukan di desa Juru mapin Kecamatan Buer Kabupaten Sumbawa merupakan salah satu strategi efektif untuk memberikan pemahaman kepada masyarakat terkait dampak dan bahaya narkoba.

\section{UCAPAN TERIMAKASIH}

Terima kasih pada pihak LPPM Universitas Muhammadiyah Mataram terhadap bantuan hibah ini. Kegiatan penyuluhan hukum ini memberikan manfaat terhadap kessadaran bagi masyarakat serta peran penting desa dalam pendampingan terhadap generasi terhadap bahaya narkoba ditengah masyarakat.

\section{DAFTAR RUJUKAN}

Jogloabang. (2020). UU 6 tahun 2014 tentang Desa. Www.Jogloabang.Com.

Salatun, R., \& Mina, R. (2019). PENYULUHAN NARKOBA Sebagai Upaya Preventif Peredaran Gelap Narkoba Di Masyarakat. MONSU'ANI TANO: Jurnal Pengabdian Masyarakat, 2(1). https://doi.org/10.32529/tano.v2i1.223

Setyawan, I., \& Sulistyawati, S. (2019). MEWASPADAI BAHAYA PENYALAHGUNAAN NARKOTIKA PADA KALANGAN MASYARAKAT DESA BANDAR KHALIFAH KECAMATAN PERCUT SEI TUAN KABUPATEN DELI SERDANG. Prosiding Seminar Nasional Hasil Pengabdian 2019, 451-456.

Sulistyawati, S., Iwan Setyawan, Nelvitia Purba, \& Lukman Harun Siregar. (2020). PENYULUHAN HUKUM DOUBLE TRACK SISTEM (SANKSI PIDANA DAN TINDAKAN)TERHADAP PENYALAHGUNAAN NARKOTIKA BAGI MASYARAKAT DESA BANDAR SONO KABUPATEN BATUBARA. AMALIAH: JURNAL PENGABDIAN KEPADA MASYARAKAT, 4(1), 85-90. https://doi.org/10.32696/ajpkm.v4i1.37 9

Sumbawa, W. T. (2020). Sekitar 15 RibuTerpapar Narkoba di NTB. 3 Desember.

Undang - Undang no 6 Tahun 2014. (2014). Undang-Undang Nomor 6 Tahun 2014 Tentang Desa. Undang - Undang No 6 Tahun 2014, 1, 2.

Widayati, W., \& Winanto, W. (2021). PENYULUHAN HUKUM TENTANG BAHAYA NARKOBA SEBAGAI UPAYA PREVENTIF PEREDARAN DAN PENYALAHGUNAANNYA (Desa 
Gebangsari, Kecamatan Genuk, Kota Semarang). International Journal of Law Society Services, 1(1), 24. https://doi.org/10.26532/ijlss.v1i1.1473 8 